\title{
Ecosystem Functions of Forest Park Green Belts of Urban Agglomerations as a Factor Improving the Quality of Living Standards in Conditions of Sparsely Wooded Regions
}

\author{
Kharchenko N.N. \\ Department of Ecology, Forest Protection \\ and Game Management \\ Voronezh State University of Forestry and Technologies \\ named after G.F. Morozov \\ Voronezh, Russia \\ e-mail: forest.vrn@gmail.com
}

\author{
Moiseeva E.V. \\ Department of Ecology, Forest Protection \\ and Game Management \\ Voronezh State University of Forestry and Technologies \\ named after G.F. Morozov \\ Voronezh, Russia \\ e-mail: evjen23.82@rambler.ru
}

\author{
Prochorova N.L. \\ Department of Ecology, Forest Protection and Game Management \\ Voronezh State University of Forestry and Technologies named after G.F. Morozov \\ Voronezh, Russia \\ e-mail: nadnov40@yandex.ru
}

\begin{abstract}
The creation of urban agglomerations of green forest belts is one of the conditions for the sustainable development of society. The cities of forest parks' green belts help to form the ecological framework of the territories, thereby increasing the level of quality of life of the population. The data obtained allow us to substantiate the need to create a forest-park green belt for a large urban agglomeration (Voronezh city) and to identify clear criteria for the selection of sites that will be included in it.
\end{abstract}

Keywords-green park belt, ecosystem functions, ecological frame sustainable development, quality of life.

\section{INTRODUCTION}

Nowadays urbanization is a global phenomenon. City dwellers make more than a half of the population of the planet. The influence of urban environment leads to changes and degradation of ecosystems within the boundaries of cities and suburbs. Such negative changes in ecosystems, in its turn, lead to deterioration in living standards.

Modern trends in nature management development in the Russian Federation are focused on the formation of a system of sustainable development of the region. The term "sustainable development" means such development of society in which human living conditions improve, and environmental impact remains within the economic capacity of the biosphere so that the natural basis of humanity functioning is not destroyed [10].
Sustainable urban development is impossible without neighboring forest ecosystems that perform many biospheric functions (environment forming, protective, recreational, etc.). Growth of cities causes an increase in recreational impact causing irreversible changes in the state of suburban forests. Camping is an integral part of people's lives, especially in urban areas; herewith recreation exerts a negative impact.

Natural ecosystems are characterized by resistance to external influences, including anthropogenous ones, but this resistance is not unlimited. Sustainability is determined by structuredness and hierarchy, as well as the strength of various factors influence. There is a limit in each ecosystem, beyond which it is destroyed, which invariably provokes the emergence of environmental degradation processes [8].

One of the possible ways of sustainable development to improve the quality of living standards is creation of ecological frameworks, which make a combination of ecosystems with an individual environmental management regime for each site, forming a spatially organized infrastructure that supports the ecological stability of the territory, preventing biodiversity loss and landscape degradation. An environmental framework should include the most active and ecologically interconnected spatial elements (rivers and river valleys, forest areas, etc.) on which sustainability of natural environment for a given territory depends $[1,3]$.

One of the ways to create an ecological framework around large urban agglomerations is to create forest park green belts, which solves a whole range of sensitive bioclimatic, 
environmental, social and economic problems of society. The Russian government, realizing the significance of these issues in 2016, supplemented the Federal Law "On Environmental Protection" by Chapter IX.1 "Forest Park Green Belts", which entered into force on January 1, 2017 [4].

The key idea of this change is legislative confirmation that created forest park green belts are zones with limited use of natural resources and other economic activities, including the territories on which forests are located, and the territories of the green fund within the boundaries of urban settlements adjacent to these forests or form a single natural ecological system with them.

The concept of green belts was first proposed by Sir Ebenezer Howard (1850-1928) in the UK. Sir Howard used green belts in urban greening plans to separate residential and industrial areas. The Green Belt concept was officially proposed to the Greater London Regional Planning Committee in 1935. Since then, it has been adopted by many countries in Europe and Asia. The Beijing Green Belt was created in 1956 and has an area of over $12,300 \mathrm{~km}^{2}$. The green belt of Seattle is $1,450 \mathrm{~km}^{2}$, Toronto $-7,300 \mathrm{~km}^{2}$, Frankfurt $-80 \mathrm{~km}^{2}$. Thus, the role of forest park green belts in biodiversity conservation, rational nature management and improving living standards of urban agglomeration populations is great and it is an integral part of modern existence of our society $[6,7]$.

The purpose of our research is theoretical substantiation and development of an algorithm for creating a forest park green belt in the city of Voronezh, which is a large urban agglomeration located in the forest-steppe zone.

\section{MethodS AND MATERIALS}

The Voronezh region is located in the central part of the East European Plain, in the basin of the middle stream of the Don River, at a junction of forest-steppe and steppe zones. The territory of the region is 52.2 thousand square $\mathrm{km}$; it is the third largest region in the Central Federal District. The total area of forests in Voronezh region was 506.0 thousand hectares as of January 1, 2017. The area of forest areas in Voronezh region is 464.6 thousand hectares. Forest cover of the region is $8.1 \%$, which makes it possible to consider it to be a sparsely wooded area.

According to the forest classification introduced by the Forest Code of the Russian Federation, all the forests of the Voronezh region belong to protective forests that are to be developed in order to preserve environment-forming, water protective, protective, sanitary and hygienic, health and other useful functions of forests with simultaneous use of forests, if this use is compatible with designated purpose of protective forests and useful functions performed by them [5].

Voronezh is located on the banks of the Voronezh River, 12 kilometers from its influx into the Don. The population of the city of Voronezh as of January 1, 2018 is 1,058,547 people. There is an agglomeration with a population of over
1.3 million people around Voronezh, which has a significant impact on adjacent ecosystems.

Voronezh Upland Oak Forest is located on the upland right bank of the Voronezh River to the north of the regional center. It is a large oak solid wood, preserved from a continuous strip of right-bank forests stretching up to the north from the mouth of the Voronezh River. The area of the oak forest is more than 3,000 hectares and it should be the basis of forest park green belt of the city.

The following methods have been used during the research to substantiate the need to create a forest park green belt around the city of Voronezh and to develop a methodology for its creation: methods for collecting and processing environmental data with justification of the choice of observation objects; methods of factor, expert and comparative analysis; methods of the phytoecological approach; a prioritization method; a priori ranking method; methods for evaluation of ecological parameters of forest ecosystems; empirical generalization [2].

\section{RESULTS}

Studies on the ecological and biological state of the sites in Voronezh Upland Oak Forest have been conducted to substantiate the need to create a forest park green belt in the city of Voronezh.

Recreation affects the vegetation of forest ecosystems located in close proximity to cities in different ways. As a result, tree trunks are damaged; roots come to the surface which provokes the spread of pests and development of diseases, and conditions for reforestation change resulting in a general disruption of the ecosystem dynamics. Abundance of underbrush is reduced in recreation, its species composition changes. Shrub layer and grass cover are also transformed.

Recreational influence on the state of forest stand is manifested in various consequences. There is a mechanical effect on the trees, through the damage of trunks which leads to disruption of vital activity, as well as contributes to the development of diseases and colonization of pests. Soil compaction, changes in its water and air conditions, plant nutritional conditions are caused by trampling [2,9]. Table 1 submits data characterizing the dependence on the level of recreational load of quantitative indicators of the state of forest stand.

The obtained results indicate that with an increase in the recreational load, the percentage of trees with unsatisfactory state has increased 3 times, reaching $45 \%$ by the $\mathrm{V}^{\text {th }}$ stage of digression.

Regardless of the species composition, woody plants are adversely affected by recreation. However, hardwoods are proved to be more resistant to recreational effects. 
TABLE I. STATE OF TREE STAND AT DIFFERENT STAGES OF RECREATIONAL DIGRESSION

\begin{tabular}{|c|c|c|c|c|c|}
\hline \multirow{2}{*}{ Object } & \multicolumn{5}{|c|}{ Digression Stages } \\
\hline & $\mathbf{I}$ & II & III & IV & $\mathbf{V}$ \\
\hline Crown density, $\%$ & $70-75$ & $65-70$ & $30-35$ & $25-30$ & $20-25$ \\
\hline \multicolumn{6}{|c|}{ Tree Condition Categories } \\
\hline Good & $24 / 96$ & $14 / 56$ & $11 / 44$ & $8 / 38$ & $4 / 18$ \\
\hline 2. Satisfactory & $4 / 4$ & $6 / 24$ & $7 / 28$ & $7 / 29$ & $8 / 37$ \\
\hline 3. Unsatisfactory & $0 / 0$ & $5 / 20$ & $7 / 28$ & $8 / 33$ & $10 / 45$ \\
\hline 3.1. Number of drying out trees & $0 / 0$ & $3 / 12$ & $4 / 16$ & $5 / 15$ & $6 / 28$ \\
\hline 3.2. Number of dried out trees & $0 / 0$ & $2 / 8$ & $3 / 12$ & $3 / 15$ & $4 / 20$ \\
\hline 4. Number of trees with bare roots & $0 / 0$ & $0 / 0$ & $1 / 4$ & $4 / 17$ & $11 / 50$ \\
\hline Total number of trees: & $28 / 100$ & $25 / 100$ & $25 / 100$ & $23 / 100$ & $22 / 100$ \\
\hline
\end{tabular}

Note: the numerator is the number of trees per $100 \mathrm{~m}^{2}$; the denominator is their share, $\%$

With increasing recreational load, the crowns density decreases from $75-90 \%$ to $25-30 \%$, which is reflected in the lighting conditions. Illumination is quite a sensitive indicator to the level of recreational load; its statistically significant increase of 5-8 times has been observed during the transition from the first to the second stage of digression. The illumination (in \% relative to the open surface) under the forest canopy at the soil level increases from 3 to $18 \%$ on average to the third stage of digression. At the fourth stage of digression with respect to the first one, it rises to $40-50 \%$ at the level of the soil and to $58-69 \%$ at the level of 1.5 meters. Variability of the indicator significantly increases (standard deviation increases 0-21 times) with intensification of recreational load.

Undergrowth development is an important indicator of changes in the forest environment under the influence of recreation. The abundance of undergrowth varies little in the first three stages of digression, sharply decreasing 1.5-2.1 times at stage IV and up to 2.8 times - at stage $\mathrm{V}$ on the territory of Voronezh Upland Oak Forest. Species diversity changes even with low recreational load. So at the I stage of digression, Viburnum opulus L., Frangula alnus Mill. and Lonicera xylosteum L., Euonymus verrucosa Scop. can be seen. However, already at the third stage of digression, these shade-tolerant and unstable to recreation species disappear due to the changes in environmental conditions, herewith compact thickets of Rubus L., Prunus Tourn., Prunus fruticosa Pall. grow wider, Corylus avellana L. appears.

At the third stage of digression, separate crowded groups of underbrush up to $30-50 \mathrm{~cm}$ high are formed from lightloving species: Frangula alnus Mill., Lonicera xylosteum L.
In actively visited zone (IV-V stage of digression) the undergrowth almost completely disappears in the surveyed areas; or a shrub layer is formed, represented by single individuals.

Evaluation of the state of the undergrowth at the studied object has been carried out according to the quantity, species diversity and biometric indicators. At the I-III stages of digression the undergrowth is mainly dominated by the species composing the 1 stand: Quercus robur L., Tilia cordata Mill., Betula L., Ulmus L., Populus L., Acer platanoides L., Fraxinus excelsior L. etc. There is only Acer platanoides $L$. in the undergrowth by the fifth stage.

At I-II stages of digression, the amount of undergrowth is up to 8 ind. $/ 100 \mathrm{~m}^{2}$. At III and IV stages of digression, the amount of undergrowth decreases 2.2 times, and with the greatest impact (V stage) there is no undergrowth.

Low recreational load (I-II stage of digression) does not inhibit the growth of undergrowth. Undergrowth plants have high biometric characteristics: height is up to $3.5 \mathrm{~m}$ and the trunk diameter - 3-4 cm. Their condition worsens with the growth of recreation. At the III-IV stage of digression, the average height of the undergrowth is sharply reduced (undergrowth, which is up to $1 \mathrm{~m}$ high aand makes up more than $40 \%$ of the total number).

Herbaceous plants respond to the changes in physical properties of soil surface layers and can be used as indicators of the stages of digression. Four ecological-cenotic groups of herbaceous plants are distinguished in relation to ecoconditions (Table 2).

TABLE II. ECOLOGICAL-CENOTIC GROUPS OF HERBACEOUS PLANTS DEPENDING ON THE STAGE OF DIGRESSION

\begin{tabular}{|c|c|c|c|c|c|}
\hline \multirow{2}{*}{ Ecological-cenotic groups } & \multicolumn{5}{|c|}{ Stages of digression } \\
\hline & I & II & III & IV & $\mathbf{V}$ \\
\hline Forest & $10 / 91$ & $9 / 90$ & $13 / 93$ & $8 / 35$ & $5 / 46$ \\
\hline Forest- meadow & $1 / 9$ & 0 & $1 / 7$ & $5 / 22$ & $2 / 18$ \\
\hline Meadow & 0 & 0 & 0 & $4 / 17$ & $1 / 9$ \\
\hline Weed & 0 & $1 / 10$ & 0 & $6 / 26$ & $3 / 27$ \\
\hline Total number of species $/ 100 \mathrm{~m}^{2}$ & 11 & 10 & 14 & 23 & 11 \\
\hline
\end{tabular}

Note: the numerator is the number of species per $100 \mathrm{~m}^{2}$; the denominator is their share, \% 
At the I-II stage of digression (with weak recreational load), about 11 species of grass plants were taken into account, mainly from the forest ecological-cenotic group (Table 2).

There is an increase in the diversity of habitat conditions at an average load, and, as a result, an increase in species diversity takes place, and herbaceous plants from other groups appear, such as forest-meadow, meadow and weed.

The largest number of species (23) in forest stand is noted at the IV stage of digression (with an increase in relative illumination of more than $28 \%$ relative to the open surface).

With an increase in recreational load, a change between groups of plants occurs. Forest species disappear and light loving, meadow and weedy species that are resistant to trampling and mechanical damage appear and begin to dominate. The appearance of meadow and weedy species is also influenced by light intensity and increase in soil density under the influence of recreation.

Aegopodium podagraria L. and Carex pilosa Scop. are dominants at the I-II stages of digression, with a total projective cover of $48-55 \%$. At the third stage of digression (at average load levels), their participation in the projective cover decreases by $9-12 \%$, and at the $\mathrm{V}$ stage of digression (actively visited territories) they completely disappear.

The proportion of species resistant to soil compaction and physical damage increases at the IV stage of digression. Impatiens noli-tangere $L$. and I. parviflora DC., Geum urbanum L., Urtica dioica L., Ajuga reptans L., Convallaria majalis $L$. can be seen in the live ground cover.

At the $\mathrm{V}$ stage of digression (with the maximum level of recreational load) species, which are most resistant to recreation, prevail in the ground cover: Plantago major L., Geum urbanum L., Taraxacum officinale Webb. and Impatiens parviflora $D C$.

In the course of the research, evaluation of living conditions of forest stand was carried out, for which four trial sites were laid, each of which was used for inventory and forest pathology survey of the stand, where its main taxation indicators were determined, enabling one to evaluate the condition of each species taking into account its pathological specificity.

Trial site number 1 (2.1 hectares) is located in the northeastern part of Voronezh Upland Oak Forest and is represented by two dozen of species with a slight dominance of Populus nigra L. Quercus robur L., Tilia cordata Mill., Betula pendula Roth. and Ulmus glabra Huds. are presented in equal shares on this site. Acer platanoides L., making only $8 \%$ on wood biomass, dominates in underwood and undergrowth. Dividing the sum of wood biomass of each species into its state category, the weighted average state category of the entire stand has been obtained, which is equal to 2.58 , which corresponds to a strong degree of attenuation.

The second surveyed area of 1.4 hectares is located to the south of the first one; it is a continuation of it, but differs significantly in composition. Quercus robur $\underline{\text { L. dominates, but }}$ Populus nigra $L_{\text {. }}$, dominated at previous site, takes only the 7 position. The weighted average category of tree condition in this area is 2.31, which corresponds to a weakened tree stand. A notable feature of this site is the presence of 5 old-growth oaks on it (more than 180 years old).

The third surveyed area of 2.0 hectares, adjacent to the first site from the south-west side, has an almost rectangular shape, is located on a gentle slope with north-east exposure. The predominant species (42\%) is Acer platanoides $L$., which also dominates in underwood and undergrowth. The second place in stock $(20 \%)$ is taken by Betula pendula Roth. Quercus robur L and Tilia cordata Mill. make 10\%. There are separate groups of Pinus sylvestris L. (6\%). The weighted average category of tree condition in this area is 2.29 , which corresponds to a weakened tree stand.

The fourth surveyed area of 2.5 hectares, just like the previous one, has a rectangular shape; it is located on a gentle slope with northeast exposure. The predominant species $(40 \%)$ is Betula pendula, but it is almost absent in underwood and undergrowth. The second place in stock (14\%) is taken by Acer platanoides $L$. by a large margin. Quercus robur $\underline{L}$. makes $12 \%$ and Tilia cordata Mill. makes $7 \%$. The weighted average category of tree condition in this area is 3.13, which corresponds to a highly weakened tree stand.

As a result of the strongest anthropogenic load, primarily recreational one, tree stands of Voronezh Upland Oak Forest are in a weakened state, it is necessary to apply methods of modern environmental management to maintain the ability to perform its biospheric functions to this ecosystem, one of which is its inclusion in the composition of forest park green belt.

One of the most important indicators of successful functioning of forest park green belt is its location, configuration and size. In the case of the city district of Voronezh, the location of forest stand has the following historically formed features: massive forests surround the city with a semi-ring from the northeast side (entering into the urban development zone with separate preserved islands) and cover it with an interrupted chain of small forest areas along the rest of the city's perimeter.

Work on the creation of forest park green belt should be implemented in stages at the regional level, being subjected to a specific algorithm of sequential actions. Firstly, the need to create such belt as a factor for improving the quality of living standards and, at the same time, preserving forest ecosystems with modern environmental management methods was scientifically justified.

Secondly, criteria for identifying and establishing the boundaries of forest park green belt around the regional administrative centers of the constituent entities of the Russian Federation were scientifically justified, taking into account the current forest, city planning and land legislation. Thirdly, drafting of regulatory legal acts defining the legal regime of economic and other activities, including usage, protection, protection and reproduction of forests of forest park green belt was being carried out. Fourthly, a procedure for removing land from forest park green belt and their compensation was developed. Fifthly, fire safety measures, methods for assessing 
the degree of pollution, cluttering and environmental welfare were envisaged. Sixthly, design of functional zones and composition of forest park green belt was carried out, taking into account the categories of land and their purpose. Seventhly, work was made to create, preserve, and operate a forest park green belt.

Selection of sites for inclusion into a forest park green belt was carried out on the basis of expert evaluation of representatives of:

- $\quad$ executive authorities of the region;

- $\quad$ regulatory authorities of the region;

- $\quad$ science and industry education in the region;

- public.

One of the most important issues arising in the creation of forest park green belts is criteria for selecting sites that should be included into a belt. We propose to use four criteria for the selection of forest areas for their inclusion in a forest park green belt: firstly, localization criterion; secondly, ecosystem loads criterion; thirdly, a type of a plot; fourthly, presence of encumbrances and restrictions.

The criterion "Green belt localization" is a sign that is the basis for the inclusion of a site into a forest park green belt, reflecting the distance of the site (proximity) from the city limits. Assessment by "Green belt localization" criterion was carried out in two stages. The first stage was expected limitation of forest park green belt within a radius for cities with population:

- more than 1 million people - radius of the forest park green belt $-60-80 \mathrm{~km}$;

- from 500 thousand to 1 million - radius of the forest park green belt $-30-40 \mathrm{~km}$;

- from 250 to 500 thousand radius of the forest park green belt - up to $20 \mathrm{~km}$.

The second stage is delimitation of areas for inclusion in the composition of the forest park green belt along quarterly glades, boundaries of forest quarters and (or) forest taxation units. The most valuable forest massifs or their parts should be included in the composition of the forest park green belt. In accordance with current legislation, the forest park green belt includes areas on which forests are located, and territories of green fund within the boundaries of urban settlements which are adjacent to these forests or constitute a single natural ecological system with them. Due to the fact that green areas do not have long-range effects (according to various studies, their direct influence is limited to $50-200 \mathrm{~m}$ depending on local conditions), large green tracts and "arteries" should be supplemented by green "capillaries". According to preliminary data, microclimate is alternately rather effectively affected by alternation of building strips and greenery with $200-400 \mathrm{~m}$ width.

The criterion "Presence of encumbrances" is a sign that is the basis for not including the site in a forest park green belt. Areas of natural and artificial origin which are not included in the composition of forest park green belt, are:

- $\quad$ polluted areas, with the presence of waste production and consumption, violations of soil cover;
- areas provided for the placement of capital construction objects or land plots on which capital construction objects are located (including construction in progress), with the exception of health care, education, recreation facilities, tourism, sports and recreation and sports activities;

- plots in respect of which an agreement on the development of a built-up area or an agreement on the integrated development of a territory has been made;

plots intended for location of federal objects, regional objects or local objects in accordance with the approved territorial planning documents and (or) territorial planning documentation, or for which a decision has been made to prepare the territory planning documentation or preparation of planning is being provided;

areas indicated in the license for the use of subsoil or, in accordance with the Law of the Russian Federation of February 21, 1992 No. 2395-I “On Subsoil”, an application has been submitted for granting the right to use a subsoil area, above which the land plot is located, a decision has been taken to make a tender or auction for the right to use such a subsoil plot, or a decision has been taken to grant such subsoil for use, or a mineral deposit, located within the boundaries of the relevant land plot, contains mineral reserves put on the state balance, or a subsoil plot is included in the list of subsoil plots of federal or local significance;

areas with subsoil plots located on them included in the federal fund of reserved subsoil plots;

- $\quad$ land plots reserved for state or municipal needs;

- $\quad$ plots seized for state or municipal needs.

The criterion "Type of plot" is a sign which is the basis for including the site in a forest park green belt, reflecting the origin of the site and its distinctive parameters:

- plots of natural origin, unique to the natural and climatic conditions of the region;

- plots of natural origin, common to the natural and climatic conditions of the region;

- plot of artificial origin, unique to the natural and climatic conditions of the region;

- plot of artificial origin, common to the natural and climatic conditions of the region.

The criterion "Ecosystem load" is a sign which is the basis for including the site in a forest park green belt, reflecting fulfillment of environmental functions by the site (microclimate regulation, groundwater level regulation, preservation of species and genetic diversity, water protection functions, etc.).

Calculations and multiple rating assessment of land (forest) plots enable one, by a method of expert assessments, to solve one of the main problems of the choice situation formation of an ordered sequence of alternatives (based on the preferences system expressed by the experts) for its subsequent processing of select sites for inclusion them in a forest park green belt.

An interactive map can be drawn up according to the criteria in order to visualize sites rating for their inclusion in a forest park green belt, taking into account the significance of 
the selected features. A map user will be able to see functional load of the plots within the forest park green belt and importance of individual forest areas (plantings) for conservancy of ecological balance of the territories. Areas selected for inclusion in a forest park green belt are sent to the authorized federal executive bodies.

\section{CONCLUSION}

Human well-being depends on nature-provided ecosystem services, such as climate stabilization, water and air purification, formation of fertile soils and their protection from erosion, nutrient turnover, productivity of natural communities, etc. All these and many other "gifts" of nature belong to society without having an obvious value and therefore not being objects of market relations. Urbanization is a natural process which is spontaneous to a large extent, and a well-considered, weighted policy of managing suburban forests in accordance with the principles of sustainable development is required in order to keep it under environmental control. An important role in this can be assigned to forest park protective belts. Performed ecological and biological analysis of the state of Voronezh Upland Oak Forest, belonging to the suburban green areas of the city of Voronezh, indicates the need for a set of measures aimed at improving their sustainability, productivity and protective and health-improving functions, which improves living standards of the population in the considered region. This task can be solved only when moving to the next level of sustainable forest management by creating a new forest and ecological objects around the city of Voronezh $-\mathrm{a}$ forest park green belt.

\section{References}

[1] O.S. Lisova, A.Ya. Grigorievskaya, O.V. Yakimenko, N.L. Prokhorov, "Protected areas as the" core "of the recreational framework of the Voronezh urban agglomeration." Forestry magazine, Voronezh, 2016, pp. 93 - 104.

[2] N.N. Kharchenko, S.S. Morkovina, Kosichenko, M.V. Skrynnikova, "Methodical approach to the creation of a green forest-park belt of urban agglomerations," Forest Engineering Journal, 2017, Vol. 7, № 4, pp. 122-133.

[3] V.N. Kalaev, E.V. Moiseeva, E.A. Nikolaev. "Conservation of biodiversity in the botanical gardens of the world." Bulletin of the Voronezh State University. Series: Geography. Geoecology. 2010. pp. 12-14.

[4] Federal'nyj Zakon ot 10.01.2002 № 7-FZ (red. ot 29.07.2017) "Ob ohrane okruzhayushchej sredy". - Available at: http://www.consultant.ru/document/cons_doc_LAW_34823/

[5] Forest plan of the Voronezh region. Retrieved from: http://ulh.govvrn.ru/Shared Documents / Forest Plan of the Voronezh region.doc

[6] A.I. Pisarenko, V.V. Strakhov, "Technology foresight and the future of forestry," Forestry, 2008, № 6, pp. 2-6.

[7] J. Boyd, S. Banzhaf, «What are ecosystem services?» Ecological Economics, 2007, № 63 (2-3), pp. 616-626.

[8] Y.E. Chee, «An ecological perspective on the valuation of ecosystem services». Biological Conservation, 2004, № 120, pp. 549-565.

[9] A.A. Martynyuk, M.K. Rafailov, "Methods of functional cost analysis in strategic planning of forestry development in modern conditions". Forest Engineering Journal, 2015, № 1, pp. 264-272.

[10] V.N. Razgulyaev, "Sustainable development: concepts and modern scientific and practical interpretation". Bulletin of Economic Integration, 2010, № 9, pp. 28-33. 